\title{
D. Hume para além da Epistemologia ${ }^{*}$
}

\author{
Carlos Alberto Ribeiro de Moura**
}

Resumo: O objetivo deste artigo é discutir a noção humiana de "crença", freqüentemente vista como um adendo "psicológico" à correta doutrina epistemológica do autor. Tenta-se sugerir que a teoria da crença não é um acréscimo exterior à filosofia de Hume, filosofia que, por seu lado, não partilha das obsessōes da epistemologia contemporânea.

Palavras-chave: Hume - crença - epistemologia.

I

É a D. Hume - garante Ayer - que remonta a filiação espiritual do positivismo lógico, e as linhas finais da Investigação, ao lançarem à fogueira os livros de metafísica, constituem um "excelente enunciado da postura positivista" (Ayer 3, p. 16). E não faltam textos, desde as primeiras páginas do Tratado, onde Hume indica que o tema clássico dos limites do entendimento será comentado agora a partir da "filosofia experimental", que nos recomendará não apenas a jamais ultrapassar a experiência na busca dos princípios últimos, como também a reconhecer a experiência como única "razão" de nossos princípios (Hume 12, p. xxii). Mas é verdade também que o epistemólogo estará em uma situação embaraçosa ao reconhecer Hume como um

"Comunicação apresentada no Colóquio "Hume", organizado pelo Departamento de Filosofia da FFLCH-USP e pela Hume Society, São Paulo, 1987.

${ }^{* *}$ Professor de História da Filosofia Contemporânea no Departamento de Filosofia da USP. 
de seus ancestrais, para logo depois ver-se obrigado a censurá-lo. Assim, o neopositivista vai elogiar Hume enquanto crítico da noção "metafísica" de causalidade, para logo depois recusar qualquer valor à teoria da crença; ela representaria o momento em que a análise filosófica se perde no "psicológico" - horribile dictu! — o que está fora de lugar em uma investigação filosófica(1). É o lado "ruim" da filosofia de Hume... Ele "substitui a análise lógica pela psicológica” (Kemp Smith 13, p. 561). E mesmo que se admita que a análise lógica não é volatilizada na psicologia, deve-se reconhecer que em Hume ambas permanecem lado a lado, o que faria com que seu projeto encontrasse um obstáculo insuperável no "costume" de acrescentar "teorias psicológicas" ao lado das "norma lógicas", quando esse domínio psicológico é por princípio mudo sobre a validade de normas que apenas a análise do epistemólogo pode legitimar. Sendo assim, no livro I do Tratado "o Hume filósofo analítico não é realmente muito compatível com o Hume psicólogo experimental" (Noxon 14, p. 132). Conseqüência: o autor se privaria agora da chance de oferecer-nos um critério para distinguir as crenças racionais das irracionais, "que é o que sem dúvida Hume procurava oferecer"(2). Afinal, como seria possível derivar um tal critério a partir de uma explicação psicológica sobre como adquirimos as crenças? As questões epistemológicas relativas à crença são "fundamentalmente normativas", devendo-se resolvê-las em termos de provas de significação, regras de demonstração e princípios de inferência. Enquanto o epistemólogo quer elaborar critérios para distinguir as "crenças racionais" das "opiniōes sem fundamento", os problemas psicológicos sobre a crença são fáticos e se calam sobre questões de validade (Noxon 14, p. 160).

Hume não conseguiu separar as crenças "racionais" das "irracionais": enquanto projeto epistemológico, o humeanismo fracassa. Ora, é interessante notar como o leitor epistemólogo reata agora com a linguagem da crítica racionalista a Hume, de Kant a Husserl: ele "não conseguiu"... E se há então um diagnóstico de fracasso especulativo, é porque não se tem nenhuma dúvida de que o projeto de Hume era exatamente aquele. Todavia, seria tão simples assim opor o bom ao mau Hume? E seria tão evidente que a crítica à metafísica especulativa teria como conseqüência indicar o domínio das "matters of fact" como campo da positividade? Afinal, a oposição entre análise filosófica/teoria 
Ribeiro de Moura, C.A., discurso (20), 1993: 99-113

psicológica pode designar não apenas um anacronismo neutro, mas uma chave hermenêtica que leve a desconhecer o sentido do projeto de Hume. E não faltam signos que possam pelo menos dar alguma força a esta suspeita.

Assim, deve-se notar que para Hume a temática da crença é suscitada pela análise da causalidade, antes de ser independente ou estar apenas "ao lado" dela. Como na inferência causal concluo algo que não me é efetivamente dado, é preciso perguntar onde radica o índice de realidade que atribuo à idéia inferida, e que vai distingui-la de uma idéia puramente imaginária. Agora, a solução dessa questão é essencial para que a causalidade possa efetivamente desempenhar o seu papel de relação por excelência da vida espiritual, relação que expande nosso mundo ao anexar ao "sistema de realidades" oferecido pela memória e pelos sentidos um outro sistema, que será visto como sendo também de realidades (Hume 12, p. 108). Ora, a questão não se colocaria se Hume não tivesse implodido a mathesis universalis, separando a necessidade matemática da necessidade física. Quem dá seu assentimento a uma proposição provada por intuição ou demonstração, está necessariamente determinado a conceber as idéias de uma maneira particular, já que tudo o que é absurdo é ininteligível e a imaginação não pode conceber nada de contrário a uma demonstração. Todavia, nos raciocínios causais esta "necessidade absoluta" não tem lugar, e a imaginação está livre para conceber "os dois lados da questão". Sendo assim, é preciso perguntar onde está a diferença entre a incredulidade e a crença (idem, p. 95). É a "análise fillosófica" que suscita a "psicológica", é o bom Hume quem exige o seu lado ruim... E não é surpreendente que a crença se coloque como problema: como agora a causalidade não é vista mais como uma conexão real entre eventos, não se pode mais admitir — como admitia Descartes - que a causa comunica realidade ao seu efeito ${ }^{(3)}$. Desde então, o índice de realidade que atribuímos ao efeito torna-se um enigma a ser solucionado.

Sendo assim, o que esta relação de dependência entre as temáticas do bom e do mau Hume poderia sugerir sobre sua imagem de epistemólogo fracassado? Talvez, que se exija de Hume algo que ele jamais poderá fornecer: um Ersatz ao racionalismo que o Tratado sistematicamente arruína, uma doutrina da família da "filosofia das ciências", sempre preocupada com os critérios de "demarcação". Todavia, uma vez expulsa a metafísica em nome da filosofia 
experimental, seria tão certo que o projeto "epistemológico" é o seu guia? Ora, ao invés de critérios de demarcação, será mais fácil, para o leitor, encontrar Hume diluindo sistematicamente algumas fronteiras. Assim, por exemplo, o que distinguiria a história da poesia épica enquanto discursos? Absolutamente nada, já que em ambas é a relação de causa a efeito que opera a conexão entre os diversos acontecimentos. Se existe diferença entre ambas, é apenas de graus, já que na poesia exige-se uma conexão "mais estrita" entre os eventos, de modo que não seria abusivo dizer que a história é poesia malfeita. Sendo assim, onde se localizaria a "demarcação"? Ora, como a "diferença entre a história e a poesia épica consiste apenas no grau das conexões que ligam uns aos outros os diferentes acontecimentos dos quais se compõe o tema, será difícil, se não impossível, determinar exatamente, com palavras, as fronteiras que as separam uma da outra. Esta é uma questão de gosto mais do que de raciocínio"(4). Donde se poder começar a suspeitar que o epistemólogo se coloca sob patrocínio indevido quando elogia Hume como um dos pais de sua disciplina, que infelizmente não teve um inteiro sucesso. Mas se é assim, onde se localiza o horizonte de Hume, se ele parece situar-se para além da epistemologia? Retornemos, por um momento, ao lado "mau" da filosofia de Hume. Retornemos à doutrina da crença.

\section{II}

De onde vem a certeza de Hume de que com a doutrina da crença ele se dirigiria a um problema inteiramente desconhecido pela tradição? ${ }^{(5)}$. Esta convicção, à primeira vista, é desconcertante. Pois se a problemática da crença visa a elucidar a diferença subjacente ao fato de que dou meu assentimento à idéia de Roma, mas não à idéia de Centauro, já que uma é real e outra fíctícia ${ }^{(6)}$, então a reivindicação de originalidade parece abusiva. Afinal, Descartes não se cansou de analisar a diferença entre as idéias fictícias e as verdadeiras, entre o possível e o efetivamente existente. E se é verdade que Hume vai recusar 0 comentário tradicional da questão, ao recusar que a "existência" seja algum "predicado real"(7), isto representa rejeitar uma resposta, não introduzir uma questão original. Mas então em que, exatamente, o problema a que se refere a crença foi negligenciado pelos filósofos? Invertamos a ordem das questões e 
Ribeiro de Moura, C.A., discurso (20), 1993: 99-113

investiguemos se a novidade da resposta de Hume a um problema aparentemente tradicional pode indicar em que este problema mudou de sentido o suficiente para tornar-se irreconhecível no interior do passado filosófico.

Conhece-se a resposta de Hume: uma crença é apenas uma idéia que difere da ficção pela maneira em que é concebida. Uma idéia à qual assentimos é "sentida" de outra forma que uma idéia fictícia, e será para designar esta diferença de sentimento que se falará que a idéia na qual se crê tem uma superioridade de "força e vivacidade" (Hume 12, $3^{\mathrm{a}}$ parte, seção VII). Todavia, o que designam essas qualidades "psicológicas" para ter a incumbência de separar a conviç̧ão da ficção? Se não podemos afirmar senão que o espírito sente algo que distingue as idéias do juízo das ficções da imaginação, a análise "fenomenológica" deverá ceder lugar a uma investigação genética que me mostre a origem dessa diferenciação. Será preciso perguntar de onde vem a "vivacidade" de certas idéias.

Ora, a resposta de Hume a esta questão é antes de tudo apaziguadora. Quando uma impressão se torna presente, não apenas ela conduz o espírito às idéias que the são costumeiramente ligadas, como também comunica a essas idéias uma parte de sua força e vivacidade (id. ibid., seção VIII). Desde então, a "força e vivacidade" das idéias parece designar o nome "subjetivo" de algum "índice de realidade" que teria sua origem na experiência. E seria o campo da experiência que ditaria, enfim, a diferença entre ficções e convicções. O "empirismo" viria corroborar na "demarcação". Mas sabe-se que o leitor epistemólogo que se acreditasse, enfim, em posse de algum critério seguro, iria logo depois decepcionar-se: não apenas ele não tem critério algum, como a "força e vivacidade" das idéias rapidamente deixará de solidarizar-se sempre com qualquer "índice de realidade" sussurrado pela experiência.

Porque logo depois de vincular a vivacidade das idéias a alguma impressão presente, Hume vai indicar que esta vivacidade pode ser produzida igualmente pela educação, pela poesia ou pelas paixões. E, de fato, como excluir a educação da produção da crença? Tanto nela quanto em nossas inferências causais é o mesmo princípio que age. Pois se na inferência causal não existe Senão uma ação do costume sobre a imaginação, ação graças à quạl caminhamos da aparição de um objeto à crença em outro, é o costume que preside 
também à educação. E a "repetição frequente" de uma idéia solitária fará com que ela adquira "força e vivacidade". De tal forma que a crença oriunda da educação será mesmo tão forte que se poderá dizer que "mais da metade das opiniōes que triunfam entre os homens são devidas à educação e que os princípios assim implicitamente abraçados prevalecem sobre aqueles que são devidos ao raciocínio abstrato e à experiência" (Hume 12, p. 117). Da mesma forma, as paixões favorecem a crença, e um "melancólico" é muito crédulo em relação a tudo o que favorece sua paixão predominante, assim como uma emoção passa por uma "transição fácil" à imaginação e se derrama na idéia do objeto que emociona, levando-nos a formar essa idéia com mais força e vivacidade, e fazendo-nos dar a ela nosso assentimento (idem, p. 120). E se o eloqüente convence o povo, é graças a uma narrativa que vivifica e aviva tão bem a idéia "que essa se assemelha às inferências que fazemos segundo a experiência" (idem, p. 120). De modo que a cada vez que a ação da crença nasce de outros princípios que não a verdade e a realidade, "esses outros princípios desempenham o mesmo papel e exercem sobre a imaginação uma igual sedução" (idem, p. 120).

Deveríamos dizer então que Hume fracassou em oferecer-nos um critério para distinguir as crenças racionais das "irracionais", que seria o que sem dúvida ele procurava oferecer? Ora, ele simplesmente constata que a crença, uma vez reconduzida ao sentimento, designa um fenômeno impossível de ser isolado em um âmbito determinado. Não se diga que Hume "não conseguiu" separar ficção e convicção. Pelo contrário, ele nem pensa em separá-las. E a análise da crença o leva a concluir, sim, que "ficção e convicção são algo do mesmo gênero" (idem, $3^{\mathrm{a}}$ parte, seção X). Agora, a doutrina da crença corroborará, por seu lado, com o fim da diferença clássica entre o demonstrativo, o persuasivo e o poético, enquanto domínios essencialmente distintos. É claro que esta homogeneização de gêneros não será equivalente a uma indistinção total, já que quando a vivacidade nasce de uma conjunção habitual com uma impressão presente "há sempre algo de mais poderoso e real em sua ação que na veemência da poesia e da eloquêencia" (id., ibid.). O privilégio da impressão enquanto origem da vivacidade deve ser mantido, e a reflexão e as regras gerais nos auxiliarão a discernir esta diferença. Mas que não se precipite aqui nenhu- 
Ribeiro de Moura, C.A., discurso (20), 1993: 99-113

ma demarcação rigorosa: trata-se apenas de uma diferença de graus. "Ficção e convicção são algo do mesmo gênero; mas a primeira é muito mais fraca que a segunda em suas causas e em seus efeitos" (Hume 12, $3^{\mathrm{a}}$ parte, seção X). Mas então, se a convicção designa um fenômeno homogêneo à ficção, em que esta "solução" poderia indicar o que haveria de inédito na problemática da crença?

\section{III}

Por que Descartes pode neutralizar o papel da educação, e fazer uma époché de sua influência sobre nossa "crença", relegando altivamente seus ensinamentos lá nos "prejuízos da infância"? (8). É da possibilidade desta operação, exatamente, que o Tratado não se cansa de duvidar. "Todas as opiniões e noções às quais nós fomos acostumados desde nossa infância enraízam-se tão profundamente que é-nos impossível, por todas as potências da razão e da experiência, desenraizá-las; este hábito não apenas aproxima-se por sua ação daquele que nasce da união constante e inseparável das causas e dos efeitos, mas ainda, em numerosas ocasiões, triunfa sobre ele" (id., p. 116). A atenção que Descartes prestava à educação era apenas o avesso de uma imensa desconsideração: os "filósofos" a viram apenas como uma "causa artificial, e não natural", e o desajuste de seus ensinamentos face à razão, e entre si mesmos nos diferentes tempos e lugares, fez com que eles jamais a reconhecessem, quando na verdade a educação "é constituída quase sobre a mesma base de costume e repetição que nossos raciocínios oriundos das causas e dos efeitos" (id., p. 117). Mas então onde se localiza, exatamente, a raiz desta divergência Sobre o peso que se deve atribuir à educação?

Descartes conhecia a oposição entre convencer - assentimento que se obtém através do entendimento pela força de razões que se impõem do exterior à vontade - e persuadir - adesão geralmente obtida da adequação de uma opinião aos prejuízos, aos costumes ou aos sentidos, logo, adesão oriunda das faculdades não intelectuais da alma ${ }^{(9)}$. E era essa oposição entre convencer e persuadir que Pascal retomava, ao opor duas vias pelas quais as opiniões seriam recebidas na alma; o entendimento e a vontade ${ }^{(10)}$. Nos dois casos, mutatis mutandis, opor-se-á uma adesão tributária do entendimento a uma persuasão que não tem em sua origem qualquer motivação racional, e a oposição entre 
convencer e persuadir sempre suporá a possibilidade de isolar este racional. Ora, a questão humeana da "crença" nascerá quando este isolamento do "racional" já não for mais possível, quando não houver mais nenhum sentido naquilo que Descartes compreendia por "convencer", e quando se tiver que dar conta de um assentimento que não poderá mais situar-se no quadro da velha oposição.

Porque é antes de tudo o quadro subjacente à oposição cartesiana entre convencer e persuadir que Hume vai demolir. Se o sujeito cartesiano persegue a "composição" das "naturezas simples" que está na origem dos complexos, dessa operação ele poderá obter, seja persuasão, seja convicção. É que essa composição pode fazer-se seja "por impulsão", seja "por dedução". E compomos "por impulsão" quando somos levados a crer em algo "sem ser convencidos por nenhuma razão", mas determinados apenas, seja por "alguma potência superior", seja por nossa "própria liberdade", seja por uma disposição de nossa "imaginação" (Descartes 6, p. 85). Ao contrário, obtemos "convicção" quando, pela dedução, podemos "compor coisas de tal modo que estejamos seguros de sua verdade” (idem, p. 85). A convicção será agora um fenômeno tributário de uma demonstração que recuperará uma ordem inscrita no mundo, retraçando a "ligação necessária" entre as naturezas simples que estão na origem dos compostos que se trata de conhecer. E esta "relação indissolúvel" entre os simples, nós a recuperamos quando vemos que uma coisa "está implicada confusamente no conceito de uma outra, de tal modo que nós não podemos conceber uma das duas distintamente, se nós julgamos que elas são separadas uma da outra" (idem, p. 83).

Ora, é justamente essa condição de possibilidade da "dedução" cartesiana, e da "convicção" que lhe é tributária, que Hume vai recusar ao admitir como axioma, ou "máxima geralmente aceita na filosofia", que "tudo o que é diferente é separado"(11). Agora, o comentário humeano do campo da experiência enquanto articulado em "simples" e "compostos" estará a léguas de seu equivalente cartesiano. Pois se onde existe diferença existe separabilidade, isto é, negação de toda relação(12), onde houver um ser-diferente haverá uma natureza que não implica em qualquer referência a uma outra. Agora, deveremos renunciar a qualquer "composição" por dedução, já que não há mais qualquer Logos 
Ribeiro de Moura, C.A., discurso (20), 1993: 99-113

inscrito no mundo, assim como deveremos renunciar a buscar qualquer relação interna entre aqueles dois eventos diferentes e separáveis que são a causa e o efeito $^{(13)}$.

A "convicção" que habitava o sujeito cartesiano nascia da descoberta de uma relação legítima, isto é, interna e necessária entre os conteúdos; ele era um epifenômeno da legitimidade lógica de uma dedução. No universo de Hume não haverá mais relações internas aos seus componentes, e agora a crença nasce como questão: de onde vem o assentimento se ele não é mais o resultado de um Logos inscrito no universo? A natureza da questão muda quando não há mais o "convencimento" oriundo do entendimento de um sujeito universal, sem que isso signifique que estejamos condenados a uma "persuasão" que só se definia como o negativo da razão e supunha, por isso mesmo, a sua jurisdição. A questão da crença vai designar exatamente o modo de tratar o assentimento quando ele não pode mais se situar no âmago da oposição entre razão e irrazão. A "convicção" do sujeito cartesiano era oriunda de uma evidência que se impunha excluindo o seu contrário. Ora, no campo das matters of fact não há nada que exclua o seu contrário, e assim não há mais lugar nele para a convicção racional. Ao invés da oposição entre razão e irrazão, há apenas o contínuo do mais ao menos provável, e com ele uma crença que não deve mais ser comentada sob a ótica da razão pura. E se toda relação agora é exterior aos termos relacionados, oriunda dos princípios associativos da natureza humana, se ela repousa sobre o costume, em nome do que desconhecer o "costume" oriundo da educação? Tanto na crença oriunda de uma inferência causal quanto naquela proveniente da educação, só poderá haver diferenças de grau quanto à "vivacidade" das idéias, e não deverá haver surpresa se a crença designar mais um fenômeno do sentimento que do entendimento - desde que não se veja este "sentimento" com os olhos do cartesiano, como o irracional, e mais como aquilo que nos permite ser razoáveis, sem ser racionalistas. Desde então, que sentido haveria em estigmatizar a doutrina da crença enquanto queda no "psicológico", se ela pode muito bem ser o indício de que a "validade lógica" que se quer recuperar é apenas o sonho de um visionário? 


\section{IV}

Ficção e convicção são do mesmo gênero, elas só diferem em graus. E se posso situar-me neste degradé que vai da menor à maior "força e vivacidade", será inútil pensar em reinstalar, em nome desta diferença de graus, uma diferença entre as crenças "racionais" e as "outras". Nada poderá oferecer um "critério" que decida onde termina a conviç̧ão e começa a ficção. Afinal, como determinar os graus de "força"? Como determinar os graus de uma qualidade? Hume já indicava, ao leitor epistemólogo, o quanto de tolice haveria para ele em tal discussão: “... há um tipo de controvérsia que, em decorrência da própria natureza da linguagem e das idéias humanas, envolve-se em uma perpétua ambigüidade, e não poderá jamais, por alguma precaução ou quaisquer definições que sejam, estar em estado de atingir uma certeza ou precisão razoável. São as controvérsias sobre os graus de uma qualidade ou circunstância qualquer" (Hume 9, 2a. parte). Ora, "força e vivacidade" é exatamente uma qualidade das idéias, e poder-se-á discutir ao infinito sobre o grau de força de uma idéia ou sobre o grau de beleza de Cleópatra, sem que a controvérsia tenha qualquer solução. Com efeito, qual Deus poderia oferecer a medida comum de qualidades que não são suscetíveis de exata medida? Agora, a discussão será puramente verbal, e o epistemólogo apenas reproduzirá a controvérsia entre o ateu e o teísta, ele vai "querelar sobre graus" e vai "entrar em uma controvérsia que não comporta nenhuma significação precisa nem portanto nenhuma decisão" (idem, ibid.). Da mesma forma, também será verbal a disputa entre os céticos e os dogmáticos, enquanto ela se refere aos "graus de dúvida ou de certeza em que devemos nos deixar conduzir no que se refere a todo raciocínio" (idem, ibid.). O epistemólogo, ao buscar um critério de "demarcação" apenas reproduz, em outro nível, estas mesmas disputas: ele insistirá em obter uma decisão sobre o indecidível. Mas então de onde vem sua semelhança de família com estes querelantes tradicionais? Ela virá de um comum desconhecimento do "verdadeiro ceticismo".

Tanto o dogmático quanto o cético clássicos desconhecem a natureza da crença. Um pensa em crer com razão, outro não crê porque não há razão, e este cético é agora tão ultra-racionalista quanto o dogmático, a sua recusa é o avesso de uma imensa consideração. Chega-se ao ceticismo por excesso de dogmatis- 
Ribeiro de Moura, C.A., discurso (20), 1993: 99-113

mo, e é a comum idolatria da razão pura que une estes pretensos rivais. Mas a doutrina da crença vai desvincular o assentimento do entendimento, e o verdadeiro cético não comungará agora mais nenhum valor comum com o dogmático, por isso ele vai "crer" mesmo sem se "convencer" (idem, $3^{\mathrm{a}}$ parte). E por não partilhar mais qualquer ilusão comum com o dogmatismo ele será um verdadeiro cético ${ }^{(14)}$. O cético "pirrônico" ainda concedia demasiada importância à razão dogmática; o verdadeiro cético se curva à força e vivacidade das idéias, ele crê, e nada melhor do que isso para mostrar que ele não presta mais qualquer homenagem ao Logos racional.

Ao final dos Diálogos sobre a Religião Natural, após aniquilar a legitimidade das provas analógicas da existência de Deus, Philo assente e indica que crê no Deus dos filósofos. O leitor da tradição racionalista não cessará agora de minimizar o alcance deste golpe de teatro final, porque ele não aceitará desvincular a crença da legitimidade lógica dos argumentos que a ela conduzem. Pode-se imaginar a reação de Sócrates-Platão se, ao final de um diálogo, seu improvável interlocutor afirmasse aceitar uma tese mas não a dialética que conduziu a ela? O leitor racionalista se espanta porque habituouse a pensar a crença como resultado exclusivo de uma Analítica, no sentido aristotélico da palavra, enquanto o Tratado não fez senão cindir sistematicamente a relação da crença com o entendimento. Agora, no espaço deixado vago pela Analítica haverá lugar apenas para uma Retórica. E só poderemos habitar um mundo exclusivamente retórico quando expulsarmos dele qualquer Logos racional. Se "não existe conexão que se possa descobrir entre os objetos", então quando estou convencido de um princípio trata-se apenas "de uma idéia que me afeta de maneira mais forte"; se prefiro uma série de argumentos a outra, "não faço senão decidir segundo a maneira pela qual sinto a superioridade de sua influência", e não será "apenas na poesia ou na música que devemos seguir nosso gosto e nosso sentimento; ocorre o mesmo na filosofia" (idem, 3a. parte, Seção VIII). Philo não se "convence" como o sujeito cartesiano o faria. Mas e daí? Sob o ângulo estrito da Razão Pura haveria muito mais fraude nos argumentos analógicos que na mais corriqueira inferência causal? Em um caso como no outro a razão não preside mais à inferência e "cremos" em função de uma vivacidade que comporta graus. Philo não se convence, mas ele se per- 
suade, desde que não compreendamos esta "persuasão" com as tintas do "irracional" que o cartesianismo lançou sobre ela, mas no sentido mais neutro da retórica ou da dialética aristotélica: adesão oriunda de uma escolha entre possíveis, que não é aleatória, que comporta graus, mas que não se confunde com a evidência racional (Aristóteles 1, pp. 19-20). E não seria este, realmente, o único e verdadeiro ceticismo?

Abstract: The purpose of this article is to discuss the Hume's notion of "belief", currently undestood as a "psychological" addition of the author's correct epistemological doctrine. It suggests that the theory of belief is not an extrinsic addition of Hume's philosophy, a philosophy which do not know the obsessions of contemporary epistemology.

Keywords: Hume - Belief - Epistemology.

\section{Notas}

(1) Cf. Ayer 2, pp. 121-2: "a discussão de questões psicológicas está fora de lugar em uma investigação filosófica. A razão disto está em que a doutrina empirista... $\ell$ uma doutrina lógica relativa à distinção entre proposições analíticas, sintéticas e verborragia metafisica e, enquanto tal, nada tem a ver com qualquer questão fáctica de caráter psicológico."

(2) Cf. Noxon 14, p. 154 e Flew 8, pp. 211-12: "na medida em que Hume pretende realmente reduzir todas as questões relativas à racionalidade ou irracionalidade das crenças (...) a meras questões relativas a mecanismos psicológicos produtores de tais crenças, ele fecha a si mesmo a possibilidade de estabelecer uma distinção valorativa entre as crenças razoáveis sustentadas por pessoas judiciosas e instruídas $e$ as beatices e superstições com que outras pessoas enganam-se a si mesmas".

(3) Cf. Descartes 5, p. 289: “é coisa manifesta pela luz natural, que deve haver pelo menos tanta realidade na causa eficiente e total quanto em seu efeito: pois de onde o efeito pode tirar sua realidade senão de sua causa? e como esta causa lha poderia comunicar se ela não a tivesse nela mesma?" 
Ribeiro de Moura, C.A., discurso (20), 1993: 99-113

(4) Cf. Hume 10, sec. III, pp. 67-8 (que inclui os parágrafos constantes nas edições do Enquiry anteriores a 1777).

(5) Cf. Hume 12, p. 97: "Este ato do espírito jamais foi explicado por nenhum filósofo". Cf. parágrafo acrescentado ao apêndice: "Esta operação do espírito que produz a crença em um fato foi até agora, parece, um dos maiores mistérios da filosofia: ninguém todavia chegou a suspeitar que havia aqui alguma dificuldade a ser explicada". Cf. também Abstract. Paris, Aubier (bilíngüe), 1971, pp. 58-9: “O que é então esta crença? E como ela difere da simples concepção de uma coisa? Eis at uma nova questão que os filosofos negligenciaram."

(6) Cf. Hume 11, p. 47: "Nada é mais livre que a imaginação humana; se bem que ela não possa exceder o estoque primitivo das idéias fornecidas pelos sentidos externos e internos, ela tem um poder ilimitado de misturar, compor, separar e dividir essas idéias em todas as variedades da ficção e da divagação... Em que, portanto, consiste a diferença entre uma tal ficção e a crença?"

(7) Cf. Hume 12, pp. 66-7: "A idéia de existência identifica-se exatamente à idéia daquilo que concebemos como existente. Refletir sobre algo simplesmente e refletir sobre ele como sobre uma existência são dois atos que não diferem em nada um do outro. Esta idéia, se unida à idéia de um objeto qualquer, não lhe acrescenta nada. Tudo o que concebemos, nós o concebemos como existente. Toda idéia que formamos é idéia de um ser, e idéia de um ser é toda idéia que formamos."

(8) Cf. Descartes 4, p. 134: “... todas as opiniōes às quais eu dera crédito até então, eu não podia fazer melhor que de uma vez suprimi-las, a fim de substitui-las depois, ou por outras melhores, ou pelas mesmas, quando eu as tivesse ajustado à razão".

(9) Cf. Descartes 7, pp. 541-42: "Quando eu concluí a primeira vez, em decorrência das razōes contidas em minhas Meditações, que o espírito humano é realmente distinto do corpo, e que ele é mesmo mais fácil de se conhecer que ele, e várias outras coisas que são lá tratadas, eu me sentia na verdade obrigado a assentir a elas, porque eu não observava nada nelas que não fosse bem concluído, e que não fosse deduzido de princípios muito evidentes, segundo as regras da lógica. Todavia, confesso que não fui totalmente persuadido por aquilo, e que ocorreu comigo quase a mesma coisa que com os astrônomos, que, após terem sido convencidos por potentes razões de que o sol é várias vezes maior que a terra, não poderiam entretanto impedir-se de julgar que ele é menor, quando lançam os olhos sobre ele." 
(10) Cf. Pascal 15, p. 592: “ Ninguém ignora que existem duas vias pelas quais as opiniões são recebidas na alma, que são suas duas principais potências, o entendimento e a vontade. A mais natural é a do entendimento, pois não se deveria jamais consentir senão às verdades demonstradas; mas a mais comum, se bem que contra a natureza, é a da vontade, pois todos os homens são quase sempre levados a crer não pela prova, mas pelo agrado."

(11) Cf. Hume 12, p. 18: “Primeiramente nós observamos que todos os objetos que são diferentes, são discerniveis, e que todos os objetos discerniveis são separáveis pelo pensamento e pela imaginação. Podemos acrescentar aqui que essas pro. posiçōes são igualmente verdadeiras ao inverso, todos os objetos que são separáveis são discerníveis, e todos os objetos discerniveis são também diferentes."

(12)) Cf. Hume 12, p. 15: "Poder-se-ia naturalmente esperar que eu acrescentasse a diferença às outras relações; mas eu a considero antes como a negação de uma relação que como algo de real e positivo."

(13) Cf. Hume 11, p. 29: "Se um objeto se apresentasse a nós e se nos pedissem que nos pronunciássemos sobre o efeito que dele resultará sem consultar a experiência passada, de que maneira é preciso, eu vos rogo, que o espirito proceda nesta operação? É preciso que ele invente ou imagine um acontecimento que ele atribuirá ao objeto como efeito? Manifestamente, é preciso que esta invenção seja inteiramente arbitrária. $O$ espírito não pode, sem dúvida, jamais encontrar o efeito na causa suposta pela análise e o exame o mais preciso. Pois o efeito é totalmente diferente da causa e, por conseguinte, não se pode jamais descobri-lo ali. $O$ movimento da segunda bola de bilhar é um acontecimento distinto do movimento da primeira; não há nada em um que sugira a menor indicação sobre o outro". Texto que indica, com precisão, que a "volta à experiência", antes de ser uma exigência primeira da filosofia de Hume, é uma tese filosófica derivada em relação ao princípio, esse sim primeiro, segundo o qual "tudo o que é diferente é separado". $\hat{E}$ a admissão deste princípio que fará com que, a fortiori, a "experiência" seja o único texto que sobre para ser consultado.

(14) Cf. Hume 12, p. 269: “Eu posso ceder, melhor, é preciso que eu ceda à corrente da natureza submetendo-me aos meus sentidos e ao meu entendimento; $e$, por esta cega submissão, mostro perfeitamente minha disposição cética e meus princípios. " 


\section{Bibliografia}

1. Aristóteles. Art Rhétorique, Garnier, Paris, 1944.

2. Ayer, A.J. Language, Truth and Logic. Londres, Gollancz, 1954.

3. Introdução ao volume El Positivismo Lógico. México, Fondo de Cultura Economica, 1965.

4. Descartes. Discours de la Méthode. In: Oeuvres. Paris, Pléiade, 1953.

5. _ Méditation Troisième. In.: Oeuvres. Paris, Pléiade, 1953.

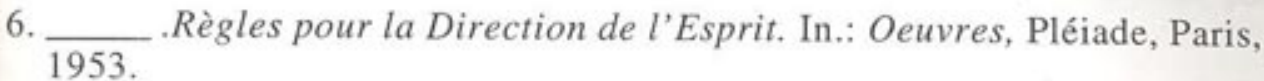

7.___. Sixièmes Réponses. In.: Oeuvres. Paris, Pléiade, 1953.

8. Flew, A. Hume's Philosophy of Belief. Londres, Routledge and Kegan Paul, 1961.

9. Hume. Dialogues concerning Natural Religion. Londres, Green \& Grose.

10. ___Enquête sur l'Entendement Humain. Paris, ed. Aubier, 1947.

11. An Enquiry concerning Human Understanding, in Hume Enquiries. Edição de Selby-Bigge. Oxford, Clarendon Press, 1958.

12. A Treatise of Human Nature. Edição de Selby-Bigge. Oxford, Clarendon Press, 1958.

13. Kemp Smith, N. The Philosophy of David Hume, Londres, Macmillan, 1941 .

14. Noxon, J. La Evolución de la Filosofía de Hume. In: Revista de Occidente, Madri, 1974.

15. Pascal. De l'Esprit Géométrique et de l'Art de Persuader. In: Oeuvres Complètes. Paris, Pléiade, 1954. 